Témoigner Témoigner. Entre histoire et mémoire

Getuigen Revue pluridisciplinaire de la Fondation Auschwitz

$126 \mid 2018$

Questions sur l'avenir du travail de mémoire

\title{
Vragen over de toekomst van de herinnering
}

Inleiding

Questions sur l'avenir du travail de mémoire. Présentation

Anneleen Spiessens et Frank Schroeder

\section{CpenEdition}

Journals

Édition électronique

URL : https://journals.openedition.org/temoigner/7133

DOI : 10.4000/temoigner.7133

ISSN : 2506-6390

Cet article est une traduction de :

Questions sur l'avenir du travail de mémoire - URL : https://journals.openedition.org/temoigner/7127 [fr]

Éditeur :

Éditions du Centre d'études et de documentation Mémoire d'Auschwitz, Éditions Kimé

Édition imprimée

Date de publication : 2 avril 2018

Pagination : 40-47

ISBN : 978-2-930953-06-9

ISSN : 2031-4183

Référence électronique

Anneleen Spiessens en Frank Schroeder, «Vragen over de toekomst van de herinnering», Témoigner. Entre histoire et mémoire [Online], 126 | 2018, Online op 24 janvier 2022, geraadpleegd op 04 février 2022. URL: http://journals.openedition.org/temoigner/7133 ; DOI: https://doi.org/10.4000/temoigner. 7133

Tous droits réservés 


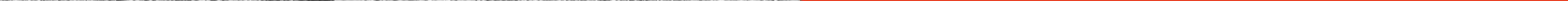




\section{Het congres in Esch-sur-Alzette}

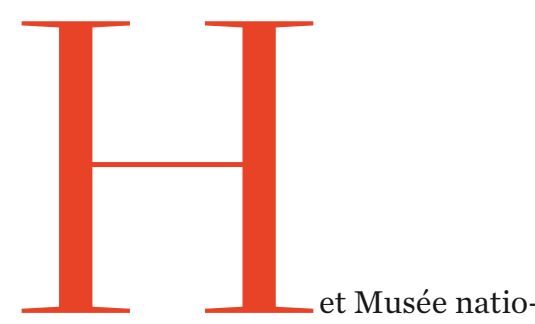

nal dela Résistance (Nationaal Museu voor het Verzet) is een bescheide project in Esch-sur-Alzette, in het zuiden van het Groothertogdom Luxemburg, en functioneert binnen een zeer specifieke herinneringscontext. De afgelopen jaren werd die grondi omgegooid door de komst van verengingen en privé-initiatieven zoals de vzw MemoShoah, een onafhankelijke burgerorganisatie die het Luxemburgse Shoah-verhaal wil belichten. Maar het is vooral dankzij politieke wil dat he herinneringswerk een nieuwe impuls heeft gekregen en de spanningen tusse verschillende groepen slachtoffers zijn afgenomen. Drie documentatiecentra sloten de deuren en nieuwe structuren zagen het licht, zoals het Comité de la Mémoire de la Deuxième Guerre mondiale, dat voortaan drie gemeenschappen samenbrengt: verzetsleden, mannen die gedwongen in dienst werkten van de Wehrmacht, en Joden Het historisch onderzoek werd toevertrouwd aan het nieuwe Institut d'histoire du temps présent/Luxembours Center for Contemporary and Digita History aan de Universiteit van Luxemburg. Een deel van het personeel van de ontbonden onderzoekscentra is daar nu aan de slag. Om de verschillende herinnerings- en herdenkingsactiviteiten te coördineren werd binnen het staatsministerie een Dienst voor de herinnering gecreeerd. Het museum van Esch vierde in 2016 haar zestigste verjaardag te midden van die grote veranderingen.

In 2016 waren in het Groothertogdom dus een aantal gloednieuw instellingen en een comité zichzel volop aan het uitvinden, en aan het brainstormen over hun taken en toekomstprojecten. Daarnaast was er on. verouderde museum, dat volgens een recente beslissing zou worden vernieuwd en uitgebreid. Het was de star van een periode van bezinning, waarin we nieuwe concepten gingen uitwerken. We kozen ervoor om een internationaal colloquing te organiseren in januari 2017 en zo het publieke debat aan te wakkeren over de toekomst van het herinneringswerk. Dat debat moes de Luxemburgse context overstijgen, zoals ook de netwerken en partnerschappen in de 'Grande Région' dat a doen (Luxemburg, Wallonië, de Franse departementen Lotharingen en Saar, en de Duitse deelstaat Rijnland-Palts), en in de geest van het Europese Interreg-programma 'Land of Memory'. Het colloquium zou voorts een openbaa nut' hebben. We zetten daarom alles in het werk om er een interactief gebeuren van te maken, waar experten en geëngageerde burgers samen konden discussierren en trajecten uittekenen voor de toekomst van de herinnering - of eerder: van het herinneringswerk. Een indrukwekkende schare aan expert maakte haar opwachting - zowel academici en onderzoekers als mensen uit het veld -, er kwam een grote verscheidenheid aan onderwerpen aan bod, de gesprekken waren uitermate boeien en we ontvingen een verrassend aant deelnemers (tussen de 120 en 150 pe panel). Kortom, het congres was op alle vlakken een groot succes.

Frank Schroede Musée national de la Résistance in Esch-sur-Alzette

\section{Voorstelling van het dossier}

DE PLAATS YAN DE SHOAH IN ONZE HERINNERINGSCULTUUR

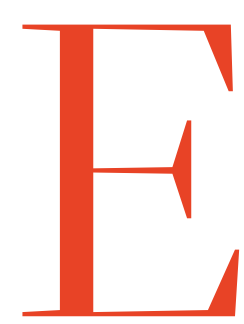
genocide op de Europese Joden worden in Rwanda 800000 Tutsi's en gematigde Hutu's vermoord in minder dan drie maanden tijd. Simone Veil heeft het gevoel dat ze wordt teruggeworpen in de tijd wanneer ze in 1994 verneemt dat in hetAfrikanseland eenvorm van geweld is uitgebroken die in vele opzichten vergelijkbaar is met degene die ze zelf heeft ondergaan, al die tijd geleden. Tijdens een dubbelinterview met Ester Mujawayo, een Rwandese overlevende, geeft ze toe dat het nieuws uit Rwanda haar aan de grond heeft genageld:

Rwanda is voor mij een bijzonder pijnlijke bladzijde in al die jaren, sinds mijn terugkeer uit het kamp. We hadden werkelijkgehoopt dat zulke barbaarse praktijken nooit meer zouden plaatsvinden.. (Mujawayo \& Belhaddad 2004, 282)

Rond dezelfde periode vertelt Innocent Rwililiza, eveneens een over- 
levende van de Rwandese genocide, he volgende aan de Franse reporter Jea Hatzfeld:

Ik las dat na elke genocide historicive ekeren dat het de laatste is. Want niemand zal ooit zulke schandelijke dade nog dulden. Wat een ongelofelijke grap. (Hatzfeld 2000, 105)

We weten ondertussen dat genocide een meervoudsvorm heeft. D Shoah was niet de eerste, en ook niet de laatste volkerenmoord van de twintigste eeuw. Door haar symbolische krach en de filosofische concepten die ze heef voortgebracht, geldt ze wel nog steeds als paradigmatisch voor de genocidaire waanzin. Catherine Coquio verwoor het zo:

Auschwitz zal altijd een brandpunt blijen van reflectie over de grenzen va het onmenselijke, een getuigenis die een maatstaf vormt voor de uitzinnige gevaren van het Duitse en Europese antisemitisme, en voor de biopolitie van de moderne natiestaat. (Coquio 1999, 55)

De auteur spoort haar lezers aa een kritische herinnering te ontwikkelen. In plaats van telkens terug te vallen op de 'plicht' om het verlede te herdenken (een bij wijlen steriel retoriek), dienen we ten volle rekenin te houden met de mogelijkheid dat de misdaad zich herhaalt, vandaag. Heidemarie Uhl beschrijft in he eerste artikel van dit dossier hoe de huidige Europese herinneringscultuur to stand is gekomen en toont aan dat het nieuwe denkkader zich uitstekend leent tot de uitwerking van een kritische herinnering. Immers, sinds midden de jare tachtig boeten ' naoorlogse mythen' nationale verhalen die focussen op het onderdrukte volk, of de verzetsheld duidelijk aan kracht in. De nieuwe generatie (de generation of memory volgen Jay Winter) erkende toen de nood aan en transnationale herinnering, die aan de basis zou liggen van een beleid met aandacht voor wereldwijde mensenrechten en solidariteit. De herinnering aan de Shoah vormt het ankerpunt van deze nieuwe, mondiale herinneringscultuur, zo schrijft de auteur. Tijdens het Stockholm International Forum on the Holocaust in 2000 ondertekenden verschillende regeringsvertegenwoordigers de 'Verklaring van Stockholm' Daarin wordt het belang van Holocausteducatie onderstreept in de strijd tegen genocide, etnische zuivering, racisme antisemitisme en xenofobie. De 31 lidstaten van de International Holocaust Remembrance Alliance (IHRA) zien erop toe dat de beginselen uit de vering overal worden toegepast.

De 'denationalisering' van de herinnering aan de Shoah staat in schril contrast met de 'nationale' definiti van de Rechtvaardige. François Wisard bespreekt in dit verband de Zwitserse casus. Het concept van bijvoorbeeld Zwitserse' of 'Franse' Rechtvaardige blijkt inderdaad weinig relevant on personen aan te duiden met een dubbele nationaliteit, redders wiens nationaliteit in de loop der jaren is veranderd, die afkomstig zijn uit landen waarvan de grenzen zijn gewijzigd, of die worden geeerd voor daden die ze in een ande land hebben verricht. Toch speelt het thema van de Rechtvaardigen, en mee algemeen dat van de redding van Joden, een grote rol in het herinneringswerk in Zwitserland. De laatste jaren werd daar een stapel aan nieuw pedagogisch materiaal ontwikkeld. François Wisard bevestigt dat de altruïstische heldenmoed, waarvoor de Rechtvaardige uiteindelijk symbool staat, ‘de leerlingen aanzet om na te denken over de keuzes de bewegingsruimte die je hebt in tragische situaties - en die waarschijnlijk groter is dan je op het eerste gezich zou denken'. Toch zijn er valkuile verbonden aan de figuur van de Rechtvaardige in Holocausteducatie. Doo voornamelijk te vertellen over 'grote exemplarische figuren' die niet noodzakelijk representatief zijn, zoals Ca Lutz of Paul Grüniger in Zwitserland, reiken leraren hun leerlingen soms een overdreven heroïsch en onbereikbaa ideaal aan, en staan ze te weinig stil bij de collectieve dimensie van veel reddingsacties.

De herinnering aan de Shoah mag vandaag dan een centrale plaats innemen in de westerse herinneringscultuur, de erkenning van die geschiedenis was niet vanzelfsprekend - en is dat no steeds niet - in Israell. Gideon Gre merkt op dat de Shoah weliswaar 'altij aanwezig is geweest in de Israëlisch samenleving en haar heeft geteken sinds de periode voorafgaand aan de oprichting van de staat'. Toch stonde de overlevende immigranten lange tij in de marge van de maatschappij. Het gedrag van de Europese Joden, die zich volgens sommigen 'als schapen naa de slachtbank hadden laten leiden', strookte niet met de basiswaarden van de nieuwe staat. Door de ArabischIsraelische oorlog van 1948 verdweehet trauma van de overlevenden no meer naar de achtergrond. Pas in 1961, tijdens het proces van Adolf Eichmann werden de Israëliërs werkelijk geconfronteerd met de schaal van de vervolging en uitroeiing van de Europese Joden. De beschouwingen van Gideo Greif in dit verband doen denken aan die van Annette Wieviorka. Zij gaf in haar standaardwerk L'Ere du témoin (2002) aan dat het proces-Eichmann een ware ommekeer betekende in de herinne- ring aan de genocide, precies omwille van de valorisatie van getuigenissen Ook in Israël zien we dat niet alleen het geschiedkundig en institutioneel werk ond de Shoah vanaf dat moment een hoge vlucht neemt (getuige het prestige van Shoah-onderzoek aan de universiteiten en het toenemende belang van Yad Vashem), maar dat daarnaast een groot corpus aan getuigenissen ontstaat. De overlevenden krijgen eindelijk een kans om deel te nemen aan het publieke debat, en de nieuwe generaties gaan op zoek naar hun plaats in de pijnlijke geschiedenis.

\section{GETUIGENIS EN OVERLEVERING}

Sinds dejaren zestigis degetuigenis, neer algemeen de ontmoeting met getuigen, dus een essentiêle pijler van het herinneringswerk rond de Shoah. Het wordt het uitgelezen middel voor overlevering, voor het doorgeven van ervaringen. Dankzij hun fragmentaire, gebroken en soms onvolledige verhalen zorgen slachtoffers van autoritaire systemen voor een affectieve en authentieke band met de grote Geschiedenis. De overlevende getuige - dat is althans de onderliggende gedachte - 'geeft een gezicht' aan de traumatische gebeurtenis, weet empathie op te wekken en zo het grote publiek te sensibiliseren. Het is dan ook verontrustend om samen met Gideon Greif vast te stellen dat de laatste rechtstreekse getuigen verdwijnen. Op hun afwezigheid werd enigszins geanticipeerd met de video-initiatieven uit de jaren negentig en 2000, aanvankelijk binnen het Fortunoff-project van Geoffrey Hartman in Yale, later de Spielberg Foundation. Maar er lijkt meer op het spel te staan dan alleen het verdwijnen van de getuigen. 
Ik keer terug naar Simone Veil en haar reactie op het nieuws uit Rwand Een nieuwe genocide, ondanks vijfti jaar van herdenkingen en vertellingen over de Shoah: wat zegt dat ove het nut van de getuigenis? Eerder da een ruptuur te veroorzaken, past die in een logica van continuiteit, zo oppe Veil. Diezelfde redenering vinden we bij Philip Gourevitch, een Amerikaan journalist en auteur van een boek over Rwanda. In mei 1994 bezoekt hij het US Holocaust Memorial Museur in Washington, en terwijl hij buite aanschuift (want net als bij elke toeristische attractie staat ook voor het museum een lange wachtrij) valt zijn blik op een foto op de voorpagina va de krant - opgezwollen lijken, drijven in een rivier:

en groep museumbeambten vatte net werbruin jasje hadden velen buttons geprikt die je voor een dollar per stuk kon kopen in de museumshop: 'Remember' - 'Neve again', las ik. Het museum bestond nog maar een jaar. Bij de opening stelde president Clinton het voor als 'een investering in een veilige toekomst tege elke vorm van waanzin die op de loe zou kunnen liggen'. Blijkbaar bedoeld hij alleen maar dat de slachtoffers va toekomstige uitroeiingen rustig konden sterven, omdat in Washingto nu een heiligdom stond waar we hu lijden zouden herdenken. Maar indertijd durfden we toch te geloven dat zijh woorden een moediger belofte inhieden. (Gourevitch 2002, 212)

De herinnering, en de getuigeni als ultiem overleveringsinstrument wordt verondersteld een barrière te vormen tegen autoritaire systemen en racisme, maar het etnische geweld in Rwanda en later ook in ex-Joegoslavie dwingen ons om de fundamenten van het herinneringswerk te herzien. In 2014 legde Philippe Mesnard de vinge al op de wonde in het editoriaal van on tijdschrift: de clichématige uitdrukking het verdwijnen van de getuigen'verhul in feite onze ontsteltenis dat we geen efficiënt model hebben gevonden voor de overlevering van een radicale collectieve ervaring. Primo Levi zelf stelde in De verdronkenen en de geredden (origineel uit 1986) het failliet vast van de getuigenis als doorgeefluik. Door haar stereotiepe vorm en structuur had ze toen al haar relevantie verloren in een steeds veranderende wereld. Dat is 'he ware probleem van onze tijd' (Mesnard $2014,5)$, en een vraag die als een rode draad doorheen de drie laatste artikel van het dossier loopt. Wie geeft wat door, en hoe?

Yariv Lapid, tussen 2007 en 2013 hoofd van de pedagogische afdeling van de Gedenkstätte Mauthausen, analyseert de dynamiek van een bezoek aan een lieu de mémoire. In tegenstelling to het traditionele parcours, waarbij de gids twee uur lang aan het woord is en het passieve publiek choqueert met een bruut verhaal, ontwikkelde Lapid een interactieve methode. Bezoekers worden aangemoedigd om op ontdekking te gaan, na te denken over de betekenis van de site vandaag en zelfstandig kennis op te bouwen. Een vlotte en rechtstreekse toegang tot bronmateriaal zoals foto's en schriftelijke getuigenissen, maar ook observatie-oefeningen blijken essentieel om de bezoekers te betrekken. Net als Heidemarie Uhl benadrukt de auteur de noodzaak om mythes te doorprikken. In dit geval is dat de 'Oostenrijkse slachtoffermythe': na een bezoek aan Mauthausen begrijpt de bezoeker da het kamp integraal deel uitmaakte van de toenmalige Oostenrijkse maatschappij en van het dorpsleven.
Ook Iris Groschek, verantwoordelijk voor de opleiding van gidsen in Neuengamme, zet voluit in op interactiviteit en participatie van bezoekers. Z onderstreept het belang van een open dialoog die toelaat dat bezoekers vanuit hun eigen achtergrond en kennis een leermoment ervaren. Voor schole ontwikkelde haar team een app waarmee leerlingen hun bezoek voorbereden en afhankelijk van hun interesse eigen onderzoeksvragen formuleren. De belangrijkste taak van de gids-begeleider in deze context is het facilitere van het debat ter plaatse. Daarnaas geeft Iris Groschek een aanzet om na te denken over de rol van nieuwe communicatiemiddelen in de overlevering va de geschiedenis. Met name social medi blijken bijzonder nuttig om jongeren te bereiken - 'elke like is een 1 remember' stelt de auteur, en de deelnemers aan het online gesprek beschouwt ze als een 'virtual community of remembrance' De aanwezigheid van gedenkplaatse in de virtuele wereld vormt bovendien een tegenpool voor 'niet gefundeerd meningen of zelfs hatespeech".

Sébastien Fevry schetst tot slo een portret van het 'postmemory-subject'. Hij gaat verder in op de kansen die het digitale tijdperk biedt en hoe dat, in afwezigheid van rechtstreekse getuigen, nieuwe vormen van overlevering mogelijk maakt. Het postmemory-subject is geen getuige of archivaris, zo betoogt hij, maar een onderzoeker van 'verweesde' beelden - beelden zonder getuigen, gevonden op het internet - en speurt naar een verleden dat hij of zij niet zelf heeft meegemaakt. Dat proce kan gezien worden als een strijd tege het vergeten, alleen vloeit het vergeten hier niet voort uit een gebrek aan documenten, maar juist uit een overvloe eraan. Via een analyse van drie werken (een strip, een onderzoeksroman en ee film) toont Sébastien Fevry aan dat de verschillende auteurs zich niets 'herinverd, maar dat ze anonieme beelden monteen en weer in hun context plaatsen, om zo een ware herinneringsdynamiek in gang te zetten.

Het mag duidelijk zijn: de toeeen groot deel af van ons vermogen en een nieuwe invulling te geven aan et herinneringswerk zoals dat aan het einde van de Tweede Wereldoorlog werd opgevat. Weldra kunnen we geen beroep meer doen op rechtstreekse getuigen van de Shoah. Decennialang deelden zij hun tragische verhalen met en onvermoeibare inzet en toewijding, en riepen zij op tot waakzaanheid. De artikels in dit dossier suggereren dat de herinnering van de toekomst transnationaal en kritisch zal zijn, ontdaan van mythes, en dat ze zal steunen op nieuwe vormen van overlevering, nieuwe herinneringsfiguren, en nieuwe manieren van herinneren.

Anneleen Spies Universiteit Gent/Stichting Auschwitz
BIBLIOGRAFIE

- Catherine Coquio, 'Du
malentendú, in Id. (red.), Parler des camps, penser les génocides, - Philip Gourevitch, Nous avons
le plaisir de vous informer que, demain, nous serons tuses rec nos familles. Chroniques
rwandaises [1998], Parijs: Denoël, 2002.

- Jean Hatzfeld, Dans le nu de la
vie. Récits des marais rwandais,

- Philippe Mesnard, 'Ce quill nous Entre Histoire et Mémoire 119, 2014, 4-5.

- Esther Mujawayo \& Souâd
Belhaddad, SurV Vivantes, Parijs:
Éditions de l'Aube, 2004

- Annette Wievorka, L'Ère du
témoin, Parijs: Hachette, 2002. 